Editorial

\title{
Importance of the international scientific research publication
}

\section{Editorial}

It aims of international publication for research to reduce the scientific gap between low and high income countries in providing access to the most recent, high quality and relevant scientific publications in the areas of agriculture, environment, Engineering, Energy and other life, physical and social sciences.

Agriculture can be considered as a basic way to sustain life on earth. Hence, MedCrave Advances in Plants \& Agriculture Research (APAR) aims to provide new and major advances in the plant and agriculture research. This particular field of journal includes but is not confined to agricultural advancements, research for plants, technical advancements to aid research for better production and various other aspects related to agriculture.

Our main aim is to provide customized services for publishing research for students and researchers from around the globe. Our aim to provide the most original, authentic and up to date research results via your respective submissions. We take care of your requirements, and ensure that your research is published in no time by the top scholars of the industry.

We have given priority to quality papers which emphasis on basic and important concept through which there would be remarkable contribution to the research area and also publish the genuine research work in the field of science, engineering and technologies and so on.

\section{General aspects}

i. Authors are invited to nominate a list of four potential expert reviewers in their accompanying letter.

ii. Reviewers must not have a conflict of interest with the authors or the paper content and not to be late to answer or accept to review of manuscript, and

iii. Editorial Board may decline or not decline to contact any of the reviewers suggested by the authors.

iv. Remaining manuscripts will be assigned to the corresponding Editor-in-Chief, which may reject or allocate them to one of the twelve Section Editors, depending on the topic. Section Editors maintain a global vision of their topic areas. They select Associate Editors, who are responsible for identifying relevant referees for single-blind peer review (the referees know the identity of the authors, but the authors do not know the identity of the referees).

v. Two referees are usually invited to comment on each submission. When the opinions of the referees differ significantly, the manuscript is usually sent to a third referee. When a decision has been reached, the decision is communicated to the author.

\section{Organization the journal into about some} partitions such as
i. Plant Science
ii. Agricultural and Food Economics

Volume 2 Issue 7 - 2015

\begin{abstract}
Abdel Rahman Ahmed
Department of Agriculture, Agricultural Engineering Research Institute, Egypt

Correspondence: Abdel Rahman Ahmed, Department of Agriculture, Agricultural Engineering Research Institute, Egypt, Tel 002-02-482544I 2, Email a_abdo_a2000@hotmail.com

Received: December 9, 2015 | Published: December 28, 2015
\end{abstract}

iii. Bio Systems

iv. Agronomy for Sustainable Development

v. Biology and Fertility of Soils

vi. Chemical and Biological Technologies in Agriculture

vii. Dairy Science \& Technology

viii. Genetic Resources and Crop Evolution

ix. Horticulture, Environment, and Biotechnology

x. Irrigation Science

xi. Energy application

xii. Optimization and Engineering

\section{Suggested that the following}

i. The Journal is a quarterly international journal that accepts research articles, reviews and short communications of content related to agriculture.

ii. Organize the conference each year, under supervisor of our Journals. It can be in different country each year.

iii. Organize the Journal to be about 8 partitions, and then each part has some papers including it. (Such as: soil and water engineering, farm machinery, farm structures, post-harvest technology, biotechnology, food processing, Plant Science and emerging technologies.).

iv. To be clear the impact factor of journal, and

v. Gave prize for the best paper, which u used more time.

\section{Acknowledgements}

None.

\section{Conflict of interest}

The author declares no conflict of interest. 